\title{
Artículo
}

\section{La negación en el náhuatl del centro de Guerrero} Negation in central Guerrero Nahuatl

\author{
Leopoldo Valiñas Coalla
}

Instituto de Investigaciones Antropológicas

Universidad Nacional Autónoma de México, México

poloval@unam.mx

Original recibido: 2016/02/13

Dictamen enviado al autor: 2016/04/04

Aceptado: 2016/08/08

\section{Abstract}

In this paper I describe the different morphosyntactic strategies that are used in Alto Balsas Nahuatl (central Guerrero Nahuatl) to mark negative sentences. Standard negation is marked by a proclitic that appears as the first element of the complex verbal word. Beyond standard negation, different negative words are used depending on the sentence type: $m a ́ k a$, if it is a negative imperative or a negative desiderative; $\lambda a ́ b m o$, if it is a negative eliptic conditional; $k a$ :, if the whole sentence is negated. The loanword nin or niu: $n$ is used as a negative copulative conjunction or as a negative nominal quantifier.

Keywords: negation, Alto Balsas Nahuatl, central Guerrero Nahuatl, negative word

\section{Resumen}

En este trabajo se describen las estrategias morfosintácticas usadas para marcar la negación en las oraciones del náhuatl del centro de Guerrero o del Alto Balsas. Se emplean recursos tanto morfológicos como sintácticos. La negación 
estándar se marca mediante un proclítico, que ocupa la primera posición de la palabra verbal compleja. Además de la negación estándar, que se marca morfológicamente, se emplean diferentes palabras negativas dependiendo del tipo de oración: máka cuando es una construcción imperativa o desiderativa negativa, $\lambda a ́ b m o$ cuando la oración es una condicional elíptica negativa, y $k a$ : cuando se niega toda la oración. También se emplea el préstamo nin o niú:n como conjunción copulativa negativa o como cuantificador nominal negativo.

Palabras clave: negación, náhuatl de Alto Balsas, náhuatl del centro de Guerrero, palabras negativas

Dedicado a Alfredo Ramirez Celestino

\section{INTRODUCCIÓN}

El objetivo central de este texto es describir los morfemas que funcionan como marcadores negativos y sus características morfosintácticas en distintas construcciones del náhuatl del centro de Guerrero o Alto Balsas, específicamente en la comunidades de Ahuelicán (AHUE), Ameyaltepec (AME), Oapan (OAP), Ozomatlán (Ozo) y Xalitla (XAL). ${ }^{1}$

El punto de partida de este texto es el aceptar que la negación es, en principio, una categoría universal, superordinaria, presente en todas las lenguas del mundo y que, por esta condición y por su relación con las

${ }^{1}$ El náhuatl del Alto Balsas es una variante lingüística que se habla en un conjunto de comunidades localizadas a ambas márgenes del río Mezcala (nombre que recibe el río Balsas en su paso por el centro de Guerrero). Se le ha asignado el Iso 639-3 ngu, aunque este incluye otras variantes del náhuatl. 
construcciones afirmativas, es una categoría estructuralmente marcada (cf. Bond 2007: 39). Dependiendo del estatus del marcador negativo o negador, se puede hablar de una negación morfológica o de una negación sintáctica (cf. Dahl 1979) y dependiendo de la relación entre las construcciones afirmativas y negativas, la negación puede ser simétrica (si las dos construcciones son estructuralmente idénticas salvo por la presencia del marcador negativo en la negativa) o asimétrica (cf. Miestamo 2005). Como se verá a continuación, la negación en el náhuatl del centro de Guerrero es simétrica manifestándose mediante los dos tipos: el morfológico y el sintáctico.

Los ejemplos de Ameyaltepec, Oapan y Ozomatlán aparecen en los textos publicados por Amith (2009), indicándose solamente la página; los ejemplos de Ahuelicán fueron proporcionados por dońa Ofelia Canuto y los de Xalitla, por don Alfredo Ramírez y doña Cleofas Ramírez. También se consultaron los materiales de Xalitla y Oapan que aparecen en Lastra (1986). ${ }^{2}$

\section{LAS NEGACIONES}

En el náhuatl del centro de Guerrero la negación es preverbal. Se emplean cinco diferentes marcadores negativos dependiendo del tipo de oración en la que aparecen y a su relación con los elementos copresentes. Uno de ellos

2 Hasta donde he logrado investigar, existen dos trabajos previos sobre este tema: uno, "Un panorama de la negación en el náhuatl del alto río Balsas", ponencia presentada en el $V$ Coloquio Leonardo Manrique en agosto del 2012 por Ma. del Carmen Herrera, Alfredo Ramírez y Maribel Alvarado. El otro, un texto de Jonathan Amith que no pude localizar. Ninguno de los dos trabajos fue consultado. 
es morfológico siendo, más precisamente, un proclítico; los otros cuatro son sintácticos. Estos cinco marcadores son:

A) Aquel con el que se niega la frase verbal de las oraciones declarativas (llamado este hecho, a partir de Payne 1985, negación estándar), y cuya forma es el proclítico $\{\hat{s}=\}$, que tiene como anfitrión al primer ítem que aparece en la palabra verbal compleja, ${ }^{3}$ sea este el verbo o cualquier construcción que funcione como el núcleo de un predicado no verbal o algún elemento de una pequeña clase de palabras que ocupa esa primera posición.

B) Aquél con el que se niega toda la oración, ka:, ka:yóweh o ká:weh, siendo él mismo una oración y, por ello, fonológicamente independiente. La tradición gramatical descriptiva de las lenguas nahuas identifica este marcador como adverbio (cf. Lastra 1980: 31; Brockway et al. 2000: 384; o Wolgemuth 2007:120) pero aquí se le identifica como marcador negativo (NEG).

C) El marcador con el que se forma el injuntivo negativo, cuyas formas son las palabras má:ka, máka: o máa y cuya posición es antes de la frase verbal. ${ }^{4}$

3 La propuesta de palabra compleja ha venido siendo discutida en el Seminario Permanente de Persona Gramatical del Instituto de Investigaciones Antropológicas de la unam. Parte de los resultados se publicaron en el Dossier "Estructura de la palabra verbal en algunas lenguas indígenas de México”, publicado en Lingüistica Mexicana (cf. Buenrostro 2010).

${ }^{4}$ A pesar de la discusión que acompaña a injuntivo como etiqueta modal, la utilizo inclu- 
D) Aquel con el que se forma la conjunción condicional negativa elíptica, cuya forma es $\lambda a ́$ ámo 'si no', resultado de la combinación del condicional $\lambda a$ con un marcador negativo. Por ser una prótasis negativa sin frase verbal, por sí mismo es una oración.

E) El marcador con el que se coordinan aditivamente enunciados negativos (en este caso identificado como conjunción negativa copulativa) o cuando funciona como un cuantificador nominal negativo, siendo su forma, en ambos casos, el préstamo del español nin, niú:n o niú:n se:

A continuación se describe cada uno de estos marcadores.

2. LA NEGACión ESTÁNDAR O LA DE LA FRASE VERbAL

Cuando una frase verbal va negada, aparece solo un marcador negati-

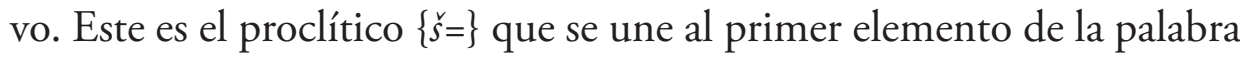
verbal compleja. Esto es, al primer elemento que aparece a la izquierda del sintagma que forman, a nivel morfológico, el verbo y uno o varios elementos preverbales (que pueden ser, además de la negación, un aspectual, algún cuantificador, alguno de los modales, uno o más de los llamados indefinidos o incluso algún adverbio).

yendo al imperativo, al exhortativo, al yusivo, al optativo y al modo en el que aparecen las oraciones que cumplen la función de complemento circunstancial de finalidad, siguiendo a Jakobson (1985 [1974]: 320). 
Aquí se retoma la propuesta sobre la existencia de tres niveles de palabra: el de la palabra afijal, la clítica y la compleja (que incluye palabras afijales). Esta última designa una construcción que conforma una unidad morfofonológica que funciona como ámbito para ciertos fenómenos (como, por ejemplo, la posición de los clíticos), amén de ciertos procesos fonológicos (como la dependencia fonológica de los auxiliares) y otros morfológicos (como los reanálisis). Esta palabra verbal compleja podría coincidir con lo que sería, en la fonología prosódica, una frase fonológica, pero debido al comportamiento de ciertos elementos morfológicos no creemos que sea el caso. Tampoco corresponde con la frase verbal porque esta no solo incluye complementos y especificadores que rebasan con creces la "solidaridad" morfofonológica que se asume existe a nivel de palabra sino que, al menos en náhuatl, no mantiene un orden rígido (cosa que la palabra verbal compleja dominantemente sí hace).

A partir de los datos obtenidos, más los presentes en los textos analizados, se puede proponer el esquema de la palabra verbal compleja $\left(\mathrm{PV}_{\text {сомр }}\right)$ como sigue (sin incluir a los adverbios, por no tener suficiente información sobre cuáles pueden ocupar dicha posición ni sobre las razones por las cuales unos sí aparecen y otros no):

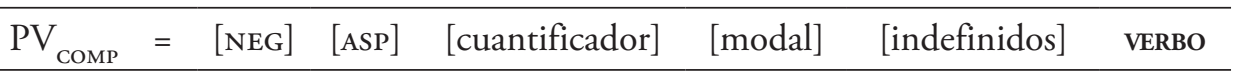

Figura 1: Esquema simple de la palabra verbal compleja ${ }^{5}$

5 Se puede proponer como riguroso el orden representado en este esquema, aunque el único componente obligatorio es la palabra verbal construida con afijos. En este trabajo, los afijos van enmarcados por \{\} . 
El primero de los elementos que aparece en el margen izquierdo de la palabra verbal compleja es el anfitrión del proclítico negativo.

A continuación, se describen brevemente las distintas maneras en las que se manifiesta la negación en la palabra verbal compleja, comenzando cuando en esta solo hay un elemento (sea el verbo o algún predicado no verbal) y siguiendo cuando, además del verbo, aparece alguno de los aspectuales, alguno de los modales, los llamados indefinidos, algún adverbio de cantidad y, finalmente, algún otro adverbio o una posposición relacional.

\subsection{Cuando en la palabra compleja solo hay un verbo}

En los casos en los que la palabra compleja está construida simplemente por un verbo, la oración se niega con el proclítico $\{\check{s}=\}$. El par de ejemplos siguientes muestra la construcción negativa pareada con su respectiva afirmativa para evidenciar su simetría. ${ }^{6}$
a. [n-iá-s] mó-čan
1sG.SJ-ir-POT 2SG.POS-casa
'Voy a ir a tu casa.' (XAL)
b. $[\check{s}=\mathrm{n}-\mathrm{i} a \dot{-}-\mathrm{s}]$
mó-čan
NEG=1sG.SJ-ir-POT
2SG.POS-casa
'No voy a ir a tu casa.' (XAL)

${ }^{6}$ Las abreviaturas aparecen al final del texto. En todos los ejemplos, la palabra verbal compleja aparece entre corchetes. 


\subsection{Cuando en el núcleo del predicado no hay verbo ${ }^{7}$}

Las oraciones cuyo predicado es no verbal también se ajustan al patrón ya descrito, aunque con ciertas particularidades -en especial, por el comportamiento de las cópulas. Antes de describir las marcas negativas en este tipo de construcciones es necesario puntualizar de manera escueta cinco hechos con respecto a las cópulas en este náhuatl:
A) La ausencia de cópula en las predicativas referenciales en tiempo pre- sente.
B) La ausencia de marcas de persona-número en la cópula en las predi- cativas referenciales en los tiempos diferentes al presente.
C) La ausencia de marcas de aspecto en el paradigma copular.
D) La supletividad morfológica de la cópula menos marcada.
E) Las dos formas léxicas de la cópula predicativa locativa y existencial.

Tomando como referencia a Hengeveld (1992), podemos decir que en este náhuatl existen dos tipos de predicados no verbales en los que se emplean las cópulas: a) las construcciones predicativas referenciales y b) las predicativas relacionales (en especial, las locativas y las existenciales). Las predicativas referenciales no requieren de la presencia de la cópula en tiempo presente, llevando la frase nominal o la adjetival el prefijo sujeto

7 Aquí se está considerando que las cópulas no son verbos, sino un tipo de operadores. Las cópulas semánticamente carecen de valencia y de estructura argumental. 
correspondiente (como se ve en $2 \mathrm{~b}$ ); mientras que en los otros tipos su presencia es predominantemente obligatoria (como se ve en 3). A continuación, se ejemplifican en pares los dos tipos de predicativas: uno de los ejemplos aparece en pasado y el otro en presente:

(2) Predicativas referenciales:

a. néhwa [ni-komisário kátka]

yo 1sG.SJ-comisario estar:PT

'Yo era/fui comisario.' (XAL)

b. néhwa [ni-komisário]

yo 1sG.SJ-comisario

'Yo soy el comisario.' (XAL)

c. in kúW $\lambda \mathrm{i}$ [ye wéyi katka]

DEM árbol ya grande estar:PT

'Este árbol ya era/estaba grande.' (XAL)

d. in kúW $\lambda$ i [ye wéyi]

DEM árbol ya grande

'Este árbol ya es/está grande.' (XAL) 
(3) Predicativas relacionales (locativas o existenciales):
a. tó-kon
[kátka
íteč kúW
1PL.POS-olla
estar:PT
junto árbol
'Nuestra olla estaba junto al árbol.' (XAL)
b. tó-kon
[únka
íteč kúW $\lambda \mathrm{i}]$
1 PL.Pos-olla
estar junto árbol
'Nuestra olla está junto al árbol.' (XAL)

c. yálWa

ayer

'Ayer yo estaba en mi casa.' (XAL)

d. áman

[n-únkah

ahora

1SG.SJ-estar

$$
\text { nó-čan] }
$$

1sG.POS-casa

'Ahora yo estoy en mi casa.' (XAL)

e. [pan

en

tépe $\lambda$

kátkan]

estar:PT:PL venados

'En el monte había venados.' (XAL)
f. [pan tépe $\lambda$ káteh] masámeh en cerro estar:PL venados
'En el monte hay venados.' (XAL)

Como se ve en los ejemplos apenas presentados, la cópula es obligatoria en todos los tiempos, excepto en presente, por ser ella la portadora de las marcas de tiempo-aspecto-modo, mas no de persona-número. Esto 
se ejemplifica en (2b) y en (4), en donde la cópula no lleva el prefijo de persona-número-sujeto (lo lleva la frase nominal o la adjetival).

(4)

$\begin{array}{llll}\text { á:man } & \text { ke:n } & \text { [ni-ríko } & \text { yes]? } \\ \text { ahora } & \text { cómo } & \text { 1sG.SJ-rico } & \text { estar:POT }\end{array}$

‘¿Ahora, cómo seré rico?' (ozo 166)

Sin embargo, es posible (mas no común) registrar algunos casos con la cópula en presente y con el prefijo de persona-número-sujeto:

$\begin{array}{llll}\text { (5) á:man } & \text { i:n } & \text { [n-ú:nkah } & \text { libre] } \\ \text { ahora } & \text { DT } & \text { 1sG.SJ-estar } & \text { libre }\end{array}$

'Ahora estoy libre.' (AME: Amith 2009: 97)

Por otra parte, en las predicativas locativas el constituyente locativo es obligatorio (sea un adverbio, un topónimo o una frase pre o posposicional), no así en las existenciales; existen casos que se registraron sin cópula, en particular, en Oapan (quizá por su valor existencial):

(6) miék te $\lambda$ ípan óh $\lambda \mathrm{i}$.

mucho piedra en:él camino

'Hay muchas piedras en medio del camino.' (oAP: Lastra 1986: 668)

En cuanto a las categorías verbales, las cópulas no distinguen aspecto, es decir, solo diferencian tiempo (presente, pasado o futuro) y modo (realis o irrealis). 
La cópula menos marcada, paradójicamente, tiene cinco alomorfos: ú:nkah, para el presente con sujeto singular; káteh, para el presente con sujeto plural; kátka, para el pasado; yes para el futuro y las formas injuntivas y la raíz ligada - $k a h$ en presente singular después de adverbios de lugar (como en nikánkah 'aquí está). ${ }^{8}$

En las construcciones predicativas locativas o existenciales con sujeto animado se emplea uno de dos lexemas: la cópula locativa genérica (ya descrita) o nemi (con el valor de cópula locativa).

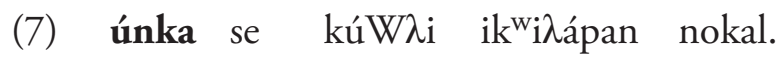

estar uno árbol detrás de mi casa

'Hay un árbol detrás de mi casa.' (xaL: Lastra 1986: 663)

(8) pa némi motáta?

allá andar tu papá

‘Está tu papá?’ (OAP: Lastra 1986: 668)

Presentados estos cinco hechos, veamos cómo se construyen las oraciones predicativas negativas. En principio, el proceso empleado es el ya descrito (es decir, se le prefija el proclítico de negación al primer elemento de la palabra compleja), ya sea al adjetivo (como en 9) o a la frase nominal (como en 10) o a otro elemento (como un adverbio, como en 11), independientemente de que aparezca la cópula, pues esta tien-

${ }^{8}$ Hay otras propuestas para describir la alomorfía de esta cópula. Asumo que sincrónicamente esta que se describe es la adecuada. 
de a ocupar dominantemente la posición final de la palabra compleja (como aparece en 9b).
a. in $\lambda$ aškahli [wélik]
DEM tortilla sabrosa
'Esta tortilla está rica.' (XAL)

b. in $\lambda$ aškahli [wélik katka]

DEM tortilla rica estar:PT

'Esta tortilla estaba rica.' (XAL)

c. in $\lambda$ aškahli [̌̌s=wélik]

DEM tortilla NEG=sabrosa

'Esta tortilla no está rica.' (XAL)

d. in $\lambda$ aškahli [řs=wélik katka]

DEM tortilla NEG=rica estar:PT

'Esta tortilla no estaba rica.' (XAL)

(10) [̌̌s=mo-siwa:w $] \quad \ldots \quad$ o:n $\quad$ y-ó:-mik

NEG=2SG.POS-mujer $\ldots$ DT ya-PF-morir

'No es tu esposa. Ella ya murió.' (ozo: Amith 2009: 191)

(11) o:n [šs=níkan í:-čan] i:n čá:neh wa:lé:wa wéhka DT NEG=aquí 3SG.POs-casa DT habitante viene de lejos 'Aquí no es su casa. La persona viene de lejos.' (ozo: Amith 2009: 147)

En las construcciones posesivas el principio de construcción es el mismo, es decir, el proclítico aparece en el margen izquierdo (a pesar de las 
aparentes excepciones). Por ejemplo, en (12) y en (13b) el proclítico se une al primer elemento del sintagma nominal, mientras que en (13c) se prefija al núcleo nominal (es decir, al que va poseído, que funciona como el núcleo del predicado no verbal). Esto se debe a que la frase nominal poseedora (en este caso, el pronombre) va topicalizada.

(12) un mé $\lambda a \lambda$ [š=téhwa m-á:ška]

DEM metate NEG=tú 2sG.POS-propiedad

'Ese metate no es tuyo.' (XaL)

a. yéhwa i-tó:ka Sántos él 3SG.POS-nombre Santos 'Su nombre es Santos.' (XaL)

b. [řs=yéhwa i-tó:ka] Sántos NEG=él 3SG.POS-nombre Santos 'Su nombre no es Santos.' (AHUE)
c. yéhwa [řsi-tó:ka] Sántos
él NEG=3SG.POS-nombre Santos
'Él, no se llama Santos.' (AHUE)

En los casos en los que el nominal o el adjetivo es un elemento léxico con el negativo como parte de él (por ejemplo, šde níkan 'extranjero',

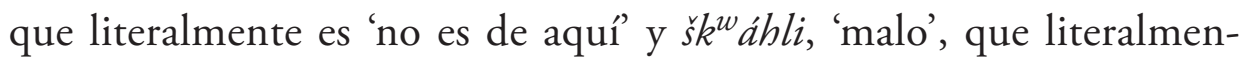
te es 'no es bueno') depende del estatus de la construcción: si ya es una 
palabra o todavía es una frase. Por ejemplo, si comparamos las oraciones de (14) con las de (15), vemos que la construcción šde níkan todavía es una frase, pues el proclítico de negación se prefija a la marca de persona-número-sujeto. En cambio, en (16), ya la negación forma parte del lexema, $s^{\prime} k^{w} a h l i$, 'no bueno = malo'. Nótese la corrección que hace el narrador en (16):

(14)
a. yéhwa [š=deníkan].
él
NEG=de aquí
'Él es extranjero.' (Lit, 'No es de aquí.') (AHUE)

b. yéhwa [deníkan].

él de aquí

'Él es de aquí.' (AHUE)

(15) a. néhwa [̌̌s=ni-deníkan].

yo $\quad$ NEG=1sG.SJ-de aquí

'Soy extranjero.' (Lit. 'No soy de aquí.') (AHUE)

b. néhwa [ni-deníkan].

yo 1 sG.sJ-de aquí

'Soy de aquí.' (AHUE)

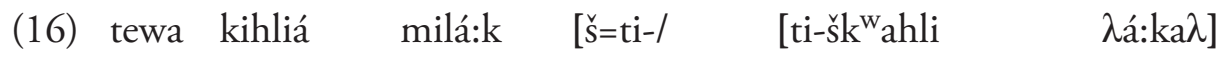
tú CUOT verdad NEG=2SG.SJ-/2SG.SJ-no bueno hombre 'Tú, le dice, en verdad tú no eres... tú eres una mala persona.'

(AME: Amith 2009: 132) 
En las construcciones predicativas locativas o existenciales negativas también el proceso es el mismo, en particular si se emplea nemi (ver 17). Pero si se usa la cópula locativa el asunto es diferente porque esta, cuando va en tiempo presente, dominantemente no lleva el proclítico de negación; se emplea en su lugar, si el sujeto es humano (o humanizado), šak - sa $a: k$ 'no estar' (ver 18a) y si es no humano, el negativo absoluto š $s a h$ 'nada, no hay, no está' (ver 19a). Advirtiendo que la [s'] de ambas formas es el proclítico de negación que, en caso de que otra forma lo hospede (por ir en el margen izquierdo de la palabra compleja), el 'no estar' aparece sin el proclítico (es decir, como $a k-a: k$, como se ve en $18 \mathrm{~b}$ ), no así el 'nada' que lo hace en su forma INDEFINIDA i $\lambda$ ah 'algo' (ver 19b). Los indefinidos y negativos absolutos se describen en $\$ 2.5$ :

(17) amánđ̛in [š=ók-a némi] ahorita NEG=alguien-INDF andar/estar 'Ahorita no hay nadie.' (AHUE)

(18)

a. š-kim-íhli ka [š=n-ak]

IMPR-3PL.O-decirle CNJ NEG=1SG.SJ-no estar

'Diles que no estoy.' (AHUE)

b. š-kim-íhli

ka [řsák-a $\mathrm{ak}]$

IMPR-3PL.O-decirle CNJ NEG= alguien-INDF no estar

'Diles que no hay nadie.' (XAL) 
(19)
a. - [únkah pólan]? $\quad-[\check{s}=\lambda$-ah $]$ estar plátano NEG=algo-INDF
- ‘Hay plátanos?' - 'No hay' / 'nada' (XAL)

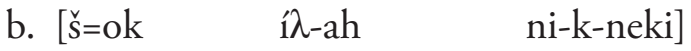 NEG=todavía algo-INDF 1sG.SJ-3SG.O-querer 'Ya no quiero nada.' (XAL)

En (20-24) se muestran algunos casos del empleo del indefinido $a k-a: k$ 'no estar'. En las oraciones (20) y (21), está hospedando al proclítico de negación y en los ejemplos (22) y (23), sin dicho proclítico, por aparecer otro elemento a inicio de la palabra compleja. La presencia de este indefinido $a k-a: k$ 'no estar' es obligatoria, junto con el proclítico de negación, independientemente del tiempo en el que vaya la oración. Véase en (24) cómo aparece el indefinido ak e inmediatamente después, sin marcas de sujeto, la cópula kátka 'estar:PT', por ser esta la que lleva la flexión de tiempo-modo en los predicados no verbales (excepto, como ya se apuntó, en las predicativas referenciales en tiempo presente, porque la cópula no aparece, como se ve en los ejemplos 20-23).
(20) $[\check{s}=\mathrm{ak}]$
kóyo: $\lambda$
NEG=no estar
coyote
‘¿No está el coyote?' (AHUE)

(21)

$\lambda$ i:n no-kní:w-a:n

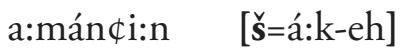

qué 1sG.POS- hermano-PL ahorita

NEG $=$ no estar $-\mathrm{PL}$

‘Y cuál de mis hermanos? Ahorita no están.' (AME: Amith 2009: 126) 
[má:ka

kí-k $\left.{ }^{\mathrm{w}} \mathrm{a}:-\mathrm{s}\right]$

NEG:IMPR

3SG.O-comer-POT фopí:lo: $\lambda$, zopilote a:mánđị

ahorita $[\check{s}=\mathrm{e}$

$\mathrm{NEG}=\mathrm{ya}$

á:k-eh]

no estar-PL

'Que el zopilote no se la coma. Ahorita todavía no hay ninguno.'

(AME: Amith 2009: 136)

(23)

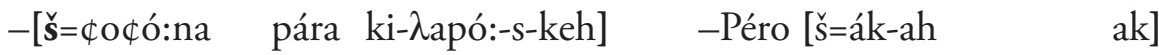
IMPR-golpear para 3SG.O-abrir-POT-PL pero NEG=alguien-INDF no estar -'Toca la puerta para que abran'. - 'Pero no hay nadie.' (xaL)

(24)

ó-n-ia

mú-čan

péro $[\check{\mathbf{s}}=\mathrm{t}-\mathrm{ak}$

katka]

PF-1sG.SJ-ir:PF

2SG.POS-casa pero NEG=2SG.SJ-no estar estar:PT

'Fui a tu casa pero no estabas.' (AHUE)

A diferencia del $i \lambda a h$ 'algo' o el š $\lambda a h$ 'nada', este $a k$ 'no estar' lleva obligatoriamente un prefijo de persona-número-sujeto y un sufijo de número (como se ve claramente en 19 y 22). ${ }^{9}$ Baste decir por ahora que su glosa pretende mostrar su valor copulativo negativo aunque, estrictamente hablando, no es un palabra-n (n-word, según la define Giannakidou 2002: 2) pues nunca aparece sola; su presencia obliga la del proclítico de negación: de no aparecer este, la construcción es agramatical. Esto se muestra a continuación:

9 Hay que advertir que el prefijo de tercera persona y el sufijo de singular son no marcados. 

a. *péro títo í-ča:n ak pero Tito 3SG.POS-casa no estar
('Pero Tito no está en su casa.') pero Tito no estar 3SG.POS-casa
('Pero Tito no está en su casa.')
b. *péro títo ak í-ča:n
c. - únka
Tito kalíhtik?
$-\check{s}=\mathrm{ak}$.
estar Tito dentro de la casa
NEG=no estar
‘ ¿ Está Tito dentro de la casa?
- No está.'
d. - únka
Tito kalíhtik?
'- ¿Está Tito dentro de la casa?
$-{ }^{*} \mathrm{ak}$.
estar Tito dentro de la casa
no estar
- No está.’

Este $a k$ tiene, además, un valor exclusivamente predicativo, cosa que no comparte con su par š̉ah 'nada, no hay, no está que, como se ve, puede cumplir con la función de cuantificador negativo (como se vio en 18).

Existen algunos ejemplos (de los que no tengo todavía ninguna explicación) en los que aparece la cópula ú:nkah 'estar' en lugar del indefinido esperado $a k$ 'no estar', en construcciones negativas. Por el momento, no tengo ninguna hipótesis razonable:

$$
\begin{aligned}
& \text { a. ke:n y-o-ni-kimin-náma:k } \quad[\check{\text { šcok }} \quad \text { ma:s ú:nkah] } \\
& \text { cómo ya-PF-1sG.SJ-3PL.o-vender:PF } \quad \text { NEG=aún más estar } \\
& \text { 'Como yo ya las vendí (las vacas), ya no hay más.' (AME: Amith 2009: 135) }
\end{aligned}
$$


b. [̌̌s=kán-a wel únka], [̌̌skán-a nel némi] NEG=lugar-INDF poder estar NEG=lugar-INDF poder andar 'No puede estar en ningún lado, no puede andar en ninguna parte'. (XAL)

2.3. Verbos acompañados por los adverbios aspectuales

Los adverbios aspectuales, que aparecen en el margen izquierdo de la palabra verbal compleja, son $o k$ 'aún' y ye - i 'ya', que se oponen entre sí en una relación bipolar. Por razones de glosas, es necesario señalar que al negarse la frase verbal se afecta su valor aspectual pero no su "valor semántico", es decir, la negación de ye 'ya' (que es še o šye o ši) no es 'ya no' sino 'todavía no':

(27) a. ok ti-фompilíwi?

aún 2SG.SJ-tener gripe

‘'Todavía tienes gripe?' (XAL)

b. $[\check{s}=\mathrm{ok} \quad$ ti- $\not$ ompilíwi $]$

NEG=aún 2SG.SJ-tener gripe

'Ya no tienes gripe.' (xaL)

(28) a. mo-tió i k-ekči:w-tíkah kóska 2SG.POS-tío ya 3SG.O-elaborar-PROG collares

'Tu tío ya está haciendo los collares.' (AHUE) 

b. mo-tío
[šs=i k-ekčí:w-tíkah]
kóskaג 2SG.POS-tío NEG=ya 3SG.O-elaborar-PROG collares 'Tu tío todavía no está haciendo los collares.' (AHUE)

\begin{tabular}{|c|c|c|c|}
\hline no-sópa & {$[\check{s}=\mathrm{ok}$} & totó:nki] & ye \\
\hline 1sG.POS-sopa & NEG=aún & caliente & ya \\
\hline
\end{tabular}

Existe una marca aspectual que funciona como un término de polaridad negativa, sa: 'ya no', que aparece solo en oraciones en injuntivo negativo y que es, por su función, la forma injuntiva negada de $o k$ 'todavía'. En (30) se muestra un ejemplo en el que el marcador negativo en injuntivo es $m a$ : (ver $\$ 4)$ :
(30) [para ma: sa: ki-pólo:-s]
para NEG:INJ ya 3SG.O-perder-POT
'Para que él ya no lo pierda (el dinero).' (OAP: Amith 2009: 73)

Existen sin embargo algunos casos en los que la construcción negativa parece ser un calco de la española, en donde el marcador negativo va en el verbo pero después de al menos un adverbio aspectual. Por ejemplo, en (31) se registra ok še ki:sa 'todavía no sale', en la que ok es 'todavía' y še es su forma negada, 'todavía no'; mientras que en (32) la forma es ye škimáti teniendo el valor de 'todavía no sabe'. Estos dos casos solo se han registrado en Ozomatlán. 
$(31)$

\begin{tabular}{|c|c|c|c|c|c|}
\hline ke:číka & [ok & $\check{\boldsymbol{s}}=\mathrm{e}$ & kí:sa] & to:nalćí:n $\lambda \mathrm{i}$ & todabía \\
\hline cuánto & aún & $\mathrm{NEG}=\mathrm{ya}$ & salir & sol & todavía \\
\hline ok & \multicolumn{5}{|c|}{ san nimánđin... } \\
\hline aún & solo lueg & & & & \\
\hline
\end{tabular}

(ozo: Amith 2009: 183) ${ }^{10}$
(32) kómo [ye š=ki-máti] i:patrón $\lambda$ a: yo:kinóhnođ o:n como ya NEG=3SG.O-saber su patrón si le platicó DEM $\lambda a: k a \pitchfork i ́ n \lambda i$
hombre
'Como todavía no sabe su patrón si ya platicó con el hombre.'

(ozo: Amith 2009: 178)

\subsection{Verbos acompañados por modales}

Los modales que aparecen en la palabra compleja son básicamente wel de posibilidad y \{-sneki\} o \{-hneki\} o la raíz ligada -neki de desiderativo. El de posibilidad es preverbal; el desiderativo merece una descripción especial. ${ }^{11}$

10 Esta oración es parte de una unidad narrativa mayor cuya lectura para mí es complicada (pues tiene varios préstamos españoles, entre ellos un negativo). Doña Ofelia, de Ahuelicán, me dio la versión en español que es la que aquí aparece como traducción. Esto, sin embargo, no afecta lo que el ejemplo pretende mostrar.

11 Con la intención de diferenciar afijos de núcleos, los primeros se representan entre llaves \{\} . 
(33)

yálWa [̌̌s=ó-wel o-ní-koč $]$

ayer NEG=PF-poder PF-1sG.SJ-dormir:PF

'No pude dormir ayer.' (XAL)

(34) níman šs=o:-kí-nek o:- $\lambda$ ák $^{\mathrm{w}} \mathrm{ah}$

luego NEG=PF-3SG.O-DES:PF PF-Comer:PF

'Entonces no quiso comer.' (ozo: Amith 2009: 176)

(35) íka $\mathrm{k}^{\mathrm{w}}$ álka:n téhwa [̌̌s=o-ti-k-nek ti- $\lambda$ ačpána-s] INST mañana tú NEG=PF-2SG.SJ-3SG.O-DES:PF 2SG.SJ-barrer-POT 'En la mañana tú no quisiste barrer.' (AHUE)

(36)

[ $\breve{s}=$ ti-wéli-s ti-ne:č-ka:wíli-s $] \quad$ ka:n

NEG=2SG.SJ-poder-POT 2SG.SJ-1so-dejarle-POT donde

ni-kóči-s?

1sG.SJ-dormir-POT

‘No podrías dejarme (un lugarcito) donde pueda yo dormir?' (AHUE)

[̌̌s=t-néki-s ti-ne:č-máka-s] ka:n ni-kóči-s?

NEG=2SG.SJ-querer-POT 2SG.SJ-1 so-dar-POT donde 1sG.SJ-dormir-POT ‘ $¡$ No quisieras darme donde pueda yo dormir?' (AME: Amith 2009: 140)

Sin entrar ahora en discusión, en este texto se considera que hay dos palabras verbales 'querer' que cumplen funciones sintácticas y gramaticales muy diferentes: una, el auxiliar desiderativo (al cual le acompaña un verbo al cual modaliza) y otra, el verbo 'querer, necesitar' de valencia 2 y que exige una frase nominal como objeto (con núcleo nominal). 
Aunque las oraciones (33) y (34) involucran distinto auxiliar modal (la primera, el de posibilidad y la segunda, el desiderativo) muestran un comportamiento paralelo: tanto los modales como sus verbos principales aparecen en pasado. La (34) es, de hecho, atípica, pues se esperaría una construcción como la de (35), en la que el verbo principal se conjuga en potencial, independientemente del tiempo del modal.

Con fines meramente descriptivos muestro tres de las construcciones prototípicas con el auxiliar desiderativo: a) la que se construye con un verbo principal mediante el sufijo $\{-$ sneki\}, $\{-$ hneki\} de desiderativo unido al verbo antes de las marcas de tiempo-aspecto-modo (ver 38); ${ }^{12}$ b) la que lleva morfológicamente al auxiliar -neki como una palabra verbal afijal (con la concordancia argumental y marcas de tiempo-aspecto-modo) siguiéndole el verbo principal conjugado en potencial (ver 39) y c) la que lleva al auxiliar -neki como morfológicamente una palabra verbal flexiva a la que le sigue el verbo principal en yusivo o imperativo (ver $40 \mathrm{y}$ 41). ${ }^{13}$ En términos simples, las dos últimas construcciones en realidad son la misma; su diferencia radica en la persona-número del sujeto del verbo principal. No está de más señalar que entre el auxiliar y el verbo principal puede haber algunos elementos léxicos (ver más adelante 46).

12 Este análisis no coincide con lo tradicionalmente hecho (por ejemplo, para el náhuatl clásico se considera un fenómeno de completiva de objeto, en donde se ve a 'querer' como el verbo principal, cf. Launey 1992 [1979]:287-289).

13 En realidad, hay una cuarta construcción que incluye a la preposición [páráa que por ahora no incluyo. 
(38) á:man ika kwálka:n meláak [ni-koči-snekí-a] hoy INST temprano verdad 1sG.SJ-dormir-DES-IMPF

'Hoy en la mañana tenía muchísimo sueño.' (Lit. 'En verdad quería dormir.')

(39) néhwa [ni-k-néki ni-k-máti-s] déke sé:meh... yo 1sG.SJ-3SG.O-DES 1sG.SJ-3SG.O-saber-POT CND uno de... 'Yo quiero saber si uno de....' (AME: Amith 2009: 127)

(40) [t-néki-s ma ni-miф-kuwíli] i:n a: $\lambda$ ? 2SG.SJ-DES-POT EXH 1SG.SJ-2SG.O-comprar DT agua ‘Quisieras que yo te comprara agua?' (AME: Amith 2009: 129)

(41) [ni-k-néki š-ne:č-kuwíli] a: $\lambda$ 1SG.SJ-3SG.O-DES IMPR-1SG.O-comprar agua 'Quiero que me compres agua.' (AHUE)

En cuanto a la negación, como ha quedado ya dicho, en todos estos casos el proclítico se une a la primera palabra o elemento de la palabra verbal compleja que aparece (las oraciones 44 y 45 son la construcción negativa de 40 y 41). Nótese en (45) la diferencia morfológica del marcador negativo $\{\dot{s}=\}$ y del imperativo $\{\dot{s}-\}$.
(42) $[\check{s}=\mathrm{t}-\mathrm{ia}-\mathrm{sneki}-\mathrm{a}]$
í-čan
Mári?
NEG=2SG.SJ-ir-DES-IMPF 3SG.POS-casa Mari
‘'No querías ir a casa de Mari?' (XAL) 
(43) wa:n [̌̌s=o-kí-nek $\lambda$ ák $^{\mathrm{w} a:-s] ~ u: n ~ M a c ̌ i ́ n . ~}$ y NEG=PF-3SG.O-DES:PF Comer-POT DT Machín 'Y Machín no quiso comer.' (AME: Amith 2009: 128)

(44) [̌̌s=t-néki-s ma ni-miф-kuwíli] i:n a: $\lambda$ ? NEG=2SG.SJ-DES-POT EXH 1sG.SJ-2SG.O-comprar DT agua ‘No quieres que yo te compre el agua?' (AME: Amith 2009: 129)

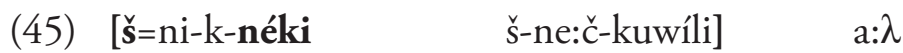
NEG=1sG.SJ-3 SG.O-DES IMP-1sG.O-comprar agua 'No quiero que me compres agua.' (AHUE)

(46) [̌̌=t-néki-s á:man sé:pan ti-nemí-s-keh] NEG=2SG.SJ-DES-POT ahora juntos 1PL.SJ-andar-POT-PL ‘No quisieras que desde ahora anduviéramos juntos?' (OAP: Amith 2009: 78)

Se entiende que si en la palabra verbal compleja va algún otro elemento (como un adverbio aspectual), si es inicial, este hospeda al proclítico negativo:

(47) $[\check{s}=$ ok ni-k-néki š-ne:č-kuwíli $] \quad$ a: $\lambda$ NEG= aún 1sG.SJ-3SG.O-DES IMPR-1sG.O-comprar agua 'Ya no quiero que me compres agua.' (AHUE) 
2.5. Verbos acompañados por los indefinidos

Los indefinidos (llamados así por los estudiosos de las lenguas yutoaztecas) identifican a la clase de pronombres y adverbios que corresponden con los interrogativos y los pronombres indefinidos de, por ejemplo, el inglés o el español (ver Hill 2005: 341). Conforman una unidad morfológica y funcionan como interrogativos, relativos, indefinidos o negativos absolutos, dependiendo de sus marcas y de los elementos que los acompañan. Su posición es fundamentalmente preverbal y por la amplia gama semántica de este conjunto, el verbo puede ir precedido por uno o varios de estos indefinidos.

\section{Tabla 1. Conjunto interrogativo-relativo-indefinido-negativo absoluto (resumido) $^{14}$}

\begin{tabular}{|c|c|c|c|}
\hline $\begin{array}{l}\text { No humano } \\
\text { Humano } \\
\text { Lugar } \\
\text { Tiempo } \\
\text { Manera }\end{array}$ & 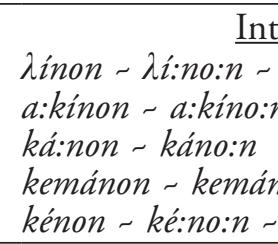 & $\begin{array}{l}\text { ggativo } \\
\text { a:kino:n o:n } \\
\text { - kamánon } \\
\text { no:n o:n }\end{array}$ & $\begin{array}{l}\text { 'Qué' } \\
\text { 'Quién', } \\
\text { 'Dónde' } \\
\text { 'Cuándo' } \\
\text { 'Cómo' }\end{array}$ \\
\hline $\begin{array}{l}\text { 'Algo’ } \\
\text { 'Alguien' } \\
\text { ‘En algún lugar' } \\
\text { 'En algún tiempo'15 } \\
\text { 'De alguna manera' }\end{array}$ & $\begin{array}{l}\text { Indefinido } \\
\text { inah } \\
\text { yákah - yékah } \\
\text { ká:nah } \\
\text { ká:nah } \\
\text { kénah - kanátsin }\end{array}$ & $\begin{array}{l}\text { Negativo absoluto } \\
\text { šlah } \\
\text { šákah - šókah } \\
\text { šká:nah } \\
\text { škéman - skáman } \\
\text { škénah - škána }\end{array}$ & $\begin{array}{l}\text { 'Nada' } \\
\text { 'Nadie' } \\
\text { 'En ningún lugar' } \\
\text { 'Nunca, } \\
\text { 'De ningún modo' }\end{array}$ \\
\hline
\end{tabular}

14 En Oapan tiende a debilitarse y perderse la $[\mathrm{k}]$ intervocálica. Esto no se registra en esta tabla.

15 En los indefinidos, la forma locativa se emplea también con valor temporal. 
Como se puede ver en la Tabla 1, los interrogativos llevan un sufijo $\{-o n\}$, que es en esencia el que indica la función interrogativa. ${ }^{16}$ En caso de no llevarlo, normalmente funcionan como relativos o conjunciones (por ejemplo, en las oraciones 36 y 37, ka:n se glosa como 'donde', aunque bien pudiera ser 'dónde', evidenciando con ello la triple función que puede tener este conjunto pronominal: la de relativo, la conjuntiva o la interrogativa). Por su parte, los indefinidos llevan la marca $\{-a b\}$ y son estos los que al negarse funcionan como negativos absolutos. En (48) se muestra la relación morfológica entre el interrogativo, el relativo, el indefinido y el negativo absoluto con la forma más transparente, la de lugar. Los otros indefinidos evidencian diversos reanálisis y algunos procesos fonológicos que oscurecen sus relaciones.

$$
\begin{array}{cll}
\text { ka:n }+ \text { on } & \text { 'dónde' } & \text { (interrogativo) } \\
\text { ka:n } & \text { 'donde' } & \text { (relativo de lugar) } \\
\text { ka: } n+\text { ah } & \text { 'en algún lugar' } & \text { (indefinido) } \\
\check{s}=[\text { ka: } n+a h] & \text { 'en ningún lugar' } & \text { (negativo absoluto) }
\end{array}
$$

Los siguientes pares de ejemplos muestran lo apenas dicho:

-a:kín-on [o-míф-mak] un yóli ? alguien-INT PF-2SG.O-dar:PF DEM Yoli - ¿QQuién te dio esa Yoli?’

16 Este sufijo se agrega después de varios cambios diacrónicos, uno de ellos un reanálisis: *a:k + in $>a: k i n>a: k i n+o n>a ́$ :kinon. En el 'qué' la función interrogativa se puede cumplir sin dicho sufijo: $\lambda i n$ tiknéki ‘¿Qué quieres?’. 
- [̌̌s=ák-ah o-né:č-mak $]$

$$
\text { NEG=alguien-INDF PF-1sG.O-dar:PF }
$$

- 'Nadie me la dio.' (AHUE)

(50) - kamán-on [o-wáhlah] Gaspár? - [̌̌=káman o-wáhlah] tiempo-INT PF-venir:PF Gaspar NEG=cuando PF-venir:PF

- ‘Cuándo vino Gaspar?’ — - 'Nunca vino.' (AHUE)

(51) - גí:no:n ti-k-íta-k?

qué 2SG.SJ-3SG.O-ver-PF

- ‘Qué viste?’

a. $-[\check{s}=\lambda$-ah $] \quad$ no: $[\check{s}=\lambda-a h \quad$ o:-ni-k-íta-k $]$ NEG=algo-INDF yo NEG=algo-INDF PF-1sG.SJ-3SG.O-ver-PF - 'Nada, no vi nada.' (ozo: Amith 2009: 184)

b. $[\check{\mathbf{s}}=\lambda-\mathrm{ah}]$

$$
\begin{aligned}
& \text { NEG=algo-INDF } \\
& \text { 'Nada.' (XAL) }
\end{aligned}
$$

Como se ve en el ejemplo (51b), los negativos absolutos si pueden funcionar ellos solos como una oración.

Ya antes se señaló que este ak tiene un valor exclusivamente predicativo (de ahí que lleve obligatoriamente marcas de persona-número). Sin embargo es evidente también su relación con el indefinido yákah 'alguien' y el interrogativo a:kinon 'quién'. A pesar de esto, he decidido glosarlo 
como 'no estar' (en lugar de 'alguien', si hubiera seguido la lógica de $r=\lambda$ - $a h$ 'NEG=algo-INDF') porque, estrictamente hablando, su comportamiento es único y, de manera simple, no tiene correlato con el conjunto de indefinidos. Esto se muestra esquemáticamente en (52). Una glosa mucho más precisa hubiera sido 'no estar alguien':

$$
\text { Interrogativo Indefinido Negativo absoluto Predicativo }
$$

No humano $\lambda$ ínon 'qué' í $\lambda$-ah 'algo' $\quad \check{s}=\lambda$-ah 'nada' $\quad * \lambda \mathrm{a}-* \lambda$ in

Humano a:kínon 'quién' yák-ah 'alguien' š=ák-ah 'nadie' ak 'no estar'

Es cierto que $\grave{s} \lambda$ ah puede funcionar con un valor predicativo, 'no hay nada', pero aquí se asume que esta construcción tiene como base el indefinido y no el interrogativo. Es decir, se niega con los indefinidos (i $i a h$ 'algo' y yá:kah 'alguien'). ${ }^{17}$

Este tema merece una atención especial porque la presencia del $a k$ alterna con ákin 'quien' (morfológicamente en su forma relativa, no interrogativa). Pareciera tener este último un valor enfático: šá:ka á:kin 'no hay (absolutamente) nadie' (en lugar del "normal” sá:ka ak 'no hay nadie').

Los indefinidos son una de las razones que nos permiten ver que no es la frase verbal, como constituyente, la que hospeda a la negación; que es la palabra verbal compleja. Obsérvese la posición que tienen ambos negativos absolutos šákah 'nadie' y š̉ $\lambda a h$ 'nada' en el siguiente par de

17 Incluso la construcción šá:ka á:kin pudiera estar relacionada con la fórmula š̀ah $\lambda$ innon 'no hay de qué' (literalmente 'nada qué'), que se emplea en respuesta a una agradecimiento. Por considerar esta última expresión más que un calco una fórmula, no digo más nada de ella en este texto. 
oraciones: aparecen antes del desiderativo. En (53), sáákah es el sujeto de la oración cuyo verbo es nopepéćo 'se le acerque' y en (54), es el cuantificador del objeto directo del verbo na:náti 'se fuera a agarrar'.

(53) yéwa ké:mah de miláa $\lambda$ awé:leh, selóso, él sí muy bravo celoso

[̌̌=ák-ah ki-néki ma no-pepéčo] sé:rka NEG=alguien-INDF 3SG.O-DES EXH RFX-acercar cerca 'Él sí que es muy celoso, no quiere que nadie se le acerque (a su esposa).' (AME: Amith 2009: 133)

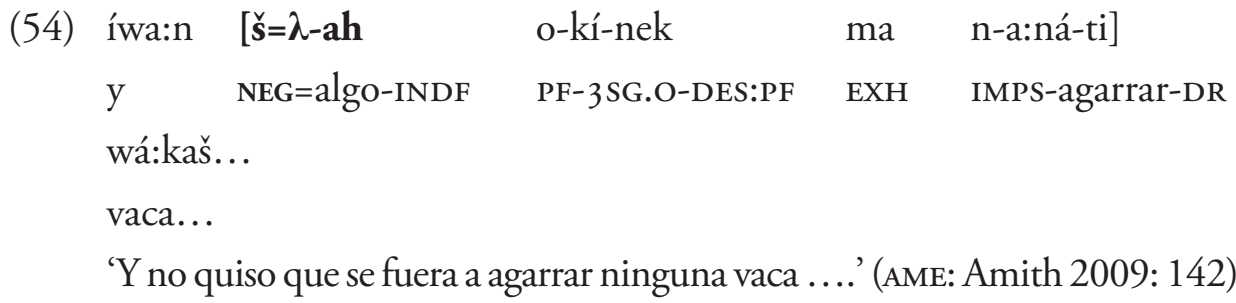

Cuando los indefinidos cumplen con la función interrogativa, normalmente (pero no obligatoriamente), se ubican por afuera de la frase verbal (como lo indican los corchetes en 55 y 56) y no pueden ir negados. Pero cuando funcionan como indefinidos o negativos absolutos forman parte, como ya se dijo, de la palabra verbal compleja. Véanse las respuestas de (55) y (56). En (55) el indefinido šákah o šókah 'nadie' funciona como sujeto mientras que en (56), lo hace como objeto y, en ambos casos, su ubicación es la misma: antes de la palabra verbal y hospedando al proclítico de negación. 
(55)

a. yák-ah [o-miçítak]?

alguien-INDF PF-te vio

- ‘Alguien te vio?’

[š=ák-ah o-ne:čítak]

NEG=alguien-INDF PF-me vio

- 'Nadie me vio.' (XAL)

b. [o-micítak] yek-áh-cin?

PF-te vio alguien-INDF-DIM

- ‘'Alguien te vio?’

[šs=ók-ah o-ne:čítak]

NEG=alguien-INDF PF-me vio

- 'Nadie me vio.' (AHUE)

(56) a. [yák-ah o-tikítak]?

alguien-INDF PF-viste

- ‘ ¿Viste a alguien?'

[̌́sák-ah o-nikítak]

NEG=alguien-INDF PF-vi

- 'No vi a nadie.' (XAL)

b. [o-tikítak yék-ah]?

PF-viste alguien-INDF

- ‘¿Viste a alguien?'

[řsók-ah o-nikítak]

NEG= alguien-INDF PF-vi

- 'No vi a nadie.' (AHUE) 
En los dos ejemplos de (57), el indefinido de lugar ká:nah o kánah carece del proclítico de negación por no ocupar la primera posición en una palabra verbal compleja que va negada.

a. [řs=ok ká:n-ah yoh $]$ ka yéhwa $[\check{s}=0 k$ NEG=aún lugar-INDF ir porque él NEG=aún $\lambda$ ačía]

ver

'Él ya no va a ningún lado porque ya no ve.' (AHUE)

b. [̌s=káman kán-ah yaw], á:man milá: y-o:-tómaw NEG=tiempo lugar-INDF ir ahora verdad ya-PF-engordar:PF 'Él nunca va a ninguna parte. Ahora engordó muchísimo.'

(ozo: Amith 2009: 177)

Veamos ahora dos casos más en los que aparecen dos o más indefinidos, destacando el ejemplo (59) en el que $i \lambda a h$ 'algo/nada' aparece postverbalmente.

(58)

néhwa [šs=ok î̉-ah yák-ah ni-k-máka] yo NEG=aún algo-INDF humano-INDF 1sG.SJ-3sG.O-dar 'Yo ya no le doy nada a nadie.' (XAL)

(59) $[\check{s}=$ ok yék-ah ni-k-máka í $\lambda$-ah] NEG=aún humano-INDF 1sG.SJ-3SG.O-dar algo-INDF 'No le doy nada a nadie.' (AHUE) 
El negativo absoluto šlah puede estar funcionando como sujeto de una predicativa locativa negativa o existencial negativa (como en 60 y 61 , cuyos significados son tanto 'no hay agua' como 'no hay nada de agua') pero también puede funcionar exclusivamente como un cuantificador nominal cuando en el predicado aparece un verbo o una cópula (en no presente), yendo antes de ellos como parte de una palabra verbal compleja (como en 62 y 63).

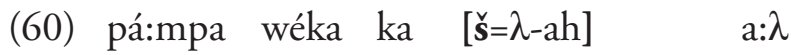
porque lejos ASP NEG=algo-INDF agua 'porque lejos (= más adelante) ya no hay agua.' (AME: Amith 2009: 127)

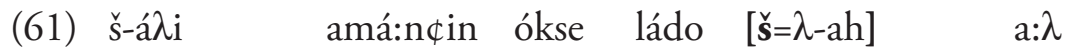
IMPR-beber ahorita otro lado NEG=algo-INDF agua 'Toma agua ahorita porque no hay agua en otro lado.' (AHUE)

(62) pórke ya milá:k [řs= $\lambda$-ah t-piáh] tomí:nđ̛i:n porque ya verdad NEG=algo-INDF 2SG.SJ-tener dinero 'Porque en verdad no tenemos nada de dinero.' (OAP: Amith 2009: 81)

(63) $[\check{s}=\lambda$-ah kátka] u:n te:patíke: $\lambda$ NEG=algo-INDF estar:PT DT doctor 'No había ningún doctor.' (AME: Amith 2009: 125)

En esta última construcción, se emplea el negativo absoluto šlah a pesar de que la frase nominal que cuantifica es [+ humana]. Al parecer 
se emplea el negativo absoluto cuando también cuantifica al nominal. Compárese con (64) en donde en una construcción semejante se usa ak 'no estar'.

(64) $[\check{s}=\mathrm{i}$ ak kátka] te:pahtiáni NEG=ya no estar estar:PT doctor

'Todavía no había doctor.' (AHUE)

\subsection{Verbos acompañados por adverbios de cantidad}

Los adverbios de cantidad o cuantificadores que aparecen dominantemente en posición preverbal son ma:s 'más', nóci 'todo' y miák 'mucho'. Los ejemplos (65-67) son más que claros. En (68), el cuantificador aparece preverbalmente pero no a principio de la palabra verbal compleja. Como es lo esperado, los cuantificadores pueden ir afuera de la palabra verbal compleja (como se ve en 69) y por ello no llevan el proclítico de negación. Finalmente, en (70) el adverbio aparece después del verbo, asumiendo que sigue siendo parte de la palabra compleja:

(65) néwa [̌̌s=ma:s ni-wekáwi-s]

yo $\quad$ NEG=más 1sG.SJ-tardarse-POT

'No me voy a dilatar mucho.' (AME: Amith 2009: 135) 
(66) níman [̌̌s=ma:s o-ki-piš-keh] tómi:n ke:n na: y-o-nikpiš luego NEG=más PF-3SG.O-tener:PF-PL dinero como yo ya-PF-tuve 'Entonces no tuvieron más dinero como yo ya lo tuve.'

(ozo: Amith 2009: 169)

(67) š-ne:šnamakí:lti! ba: néwa [̌̌=miák ni-k-néki] san se: IMPR-véndeme INTJ yo NEG=mucho 1sG.SJ-3SG.O-DES solo uno 'Véndemelo, yo no quiero tantos; solo uno.' (AME: Amith 2009: 135)

(68) ta [̌̌s=ok nóči k-ón- $\left.\mathrm{k}^{\mathrm{w}} \mathrm{i}\right]$ i-nakácii:n ?? NEG=aún todo 3SG.O-DR-agarrar 3SG.POS-carnita 'Ya no agarra toda su carne.' (AME: Amith 2009: 110)

(69) pórke san las dóse pa ninémis! ma:s [̌̌s $=$ ok n-ak yes] porque solo las doce allá andaré más NEG=aún 1SG.SJ-no estar estar:POT 'Porque hasta las doce yo podré andar allá. Más, ya no estaré.'

(ozo: Amith 2009: 169)

(70) nikíta sekímeh o-mík-eh wa:n [̌̌=ó-wel ki-píš-keh] ma:s veo algunos PF-morir-PL CNJ NEG=PF-poder 3SG.O-tener:PF-PL más 'Veo quealgunos murieron y no pudieron tener más.' (ozo: Amith 2009: 169)

2.7. Predicados acompañados por otros adverbios o posposiciones relacionales

Un detalle importante es que la cantidad de elementos que aparecen hospedando al proclítico de negación es relativamente grande. Incluye a varios 
adverbios y a posposiciones relacionales e, incluso, a la frase preposicional de la que dichas posposiciones son núcleo. ${ }^{18}$ Los primeros dos ejemplos son con adverbios y los dos últimos con posposiciones relacionales.

(71) yéhwa [š=ihkón i-tó:ka]

él NEG=así 3SG.POs-nombre

'Él no se llama así.' (AHUE)

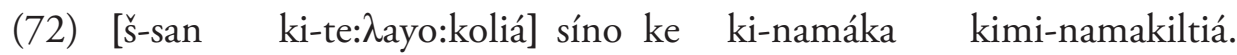
NEG=solo 3SG.O-regalar sino que 3SG.O-vender 3PL.O-venderle 'Para nada lo regala. Lo vende; se los vende.' (AME: Amith 2009: 106)

(73) [š-sé:pan ti-nemí-s-eh] NEG=juntos 1 PL.SJ-andar-POT-PL

'No viviremos juntos.' (OAP: Amith 2009: 78)

(74) ka:yóweh no: [š-í:-wa:n ni-no-na:míhti:-s]... no yo NEG=3SG.POS-con 1sG.SJ-RFX-casarse-POT 'No, yo no me voy a casar con él....' (OAP: Amith 2009: 49)

Como se dijo apenas, existen casos en los que toda una frase preposicional aparece antes del verbo, como se ve en el ejemplo que sigue:

18 Este tipo de palabras recibe varios nombres: locativos, autolocativos, sustantivos relacionales, construcciones locativo-poseídas, preposiciones, entre otros (ver por ejemplo Launey 1992 [1979]: 117 o Brockway et al. 2000: 348). Las palabras de este paradigma funcionan como preposiciones. 
(75) [š-í-tik a: $\lambda$ ti-némi $]$

NEG=3SG.POS-dentro agua 2SG.SJ-andar

'Tú no vives dentro del agua.' (OAP: Amith 2009: 46)

\section{El NEGATIVO ORACIONAL}

Un mecanismo para negar toda la oración (sea o no como una respuesta a preguntas sí/no) es el de emplear el marcador negativo, ka:, ka:yóweh o ká:weh, cuya característica básica es la de ser por sí solo una oración y por ello pronunciarse con la entonación oracional correspondiente (duda, certeza simple, certeza obvia, etc.), llevar acento y terminar con el saltillo que se inserta a final de palabra, después de vocal y antes de pausa. ${ }^{19}$
(76) - ótiah íčan mónan?
- ‘Fuiste a casa de tu mamá?'
- ka:.
- 'No.' (XaL)
(77) - ¡ šne:čwí:ka!
- ‘Llévame!'
- ka:yówe. no šnimiфwí:kas...
- 'No. Yo no te voy a llevar...'
(OAP: Amith 2009: 77)

Este recurso, como es normal, no es ni el único ni el predominante. Otro de los mecanismos para negar de manera absoluta es mediante la

19 En el náhuatl de Xalitla y Ahuelicán se inserta un saltillo después de la vocal final de una palabra que aparece antes de una pausa oracional. Por simplicidad en el registro, he decidido no representarlo en ninguno de los ejemplos. 
negación estándar, esto es, negando el verbo de la oración y pudiendo acompañarlo opcionalmente por algún complemento.

(78) - ótiah íčan mónan?

- šoniah.
- '¿Fuiste a casa de tu mamá?'

- 'No fui.' (XAL)

Y aunque en la oración haya algún constituyente topicalizado, si se niega totalmente, se usa el marcador negativo oracional:

(79) - néhwa meláak napismíktok, tehwa? - 'Tengo muchísima hambre, ¿̨tú?’ - nehwa, ka: - 'Yo, no.' (XaL)

En los textos analizados, la tendencia que se observa en la respuesta negativa a una pregunta sí/no hecha en negativo (siguiendo el mecanismo propio de la negación estándar) es que va en negativo empleándose el MARCADOR NEGATIVO oracional.

- šyéko?

- ka:, se: nokónew še yéko.
- ¿No ha llegado?'

- 'No, mi hijo todavía no llega'.

(AME: Amith 2009: 137)

Como es natural en situaciones bilingües, las formas españolas de negación pueden emplearse en conversaciones en náhuatl. Obviamente su uso lleva algún tipo de carga informacional (o fuerza ilocutiva, si se quiere). En este texto, su empleo se considera parte de las estrategias conversacionales de personas bilingües y no forma parte de la lengua náhuatl. 
$(81)$

$\begin{array}{cl}\text { - néhwa ye niáw } & \text { no no á:man }[\check{s}=t-i a ́:-s] \\ \text { yo ya voy } & \text { NEG NEG ahora NEG=2SG.SJ-ir-POT } \\ \text { - 'Ya me voy. } & - \text { No, ahora no. No irás'. (ozO: Amith 2009: 183) }\end{array}$

\section{El injuntivo NEGATIVO}

El conjunto de modos injuntivos tienen dos maneras de marcarse. El IMPERATIVO se marca mediante el prefijo $\left\{\check{s}^{-}\right\}$, que ocupa la posición de la marca de segunda persona sujeto (82), mientras que los demás (YUsIVo, OPTATIVO, EXHORTATIVO, DESIDERATIVO y los complementos de finalidad) con la conjunción ma antecediendo al verbo (ver ejemplo 83). En estos casos, si su sujeto es plural, la palabra verbal lleva el sufijo $\{-k a: n\}$. La otra manera de marcar el injuntivo es con la misma conjunción ma antecediendo al verbo (84-85) pero flexionado en potencial (o futuro, como es llamado tradicionalmente). Cuando su sujeto es plural se emplea el sufijo $\{-k e h\}$. En todos estos casos, el verbo va conjugado sobre su tema irrealis. ${ }^{20}$

(82) [̌̌- $\lambda$ ané:wti] san $\operatorname{sink}^{\mathrm{W} e ́ n t a}$ péso IMPR-prestar solo cincuenta peso ‘Préstame cincuenta pesos!' (ozo: Amith 2009: 146)

20 De manera simple, dependiendo de la conjugación a la que se sujeta un verbo, este debe aparecer en uno de cuatro temas: el largo, el corto, el irrealis y el tema-i. El irrealis se caracteriza por terminar, en ciertas clases de verbos, en vocal larga y se usa para los modos imperativo, yusivo, optativo y potencial. 
(83) déke $\mathrm{k}^{\mathrm{w} a ́}$ :hki sinkwénta peso [ma miф-wí:ka] CND traer cincuenta peso EXH 2SG.O-llevar 'Si él trae cincuenta pesos, ¡que te lleve!' (ozo: Amith 2009: 149)

(84) [̌̌-ía š-k-itá-ti] motokáyoh IMPR-ir IMPR-3SG.O-ver-DR tu tocayo 'Ve a ver a tu tocayo.' (AME: Amith 2009: 110)

(85) o-kim-íhlih [ma no-sewí:-s-keh] PF-3PL.O-decirle EXH RFX-descansar-POT-PL 'Les dijo que descansaran.' (AHUE)

La negación en este tipo de construcciones es simétrica (ver 86 y 87). El negativo se marca anteponiendo al verbo el injuntivo negativo má:ka o $m a:^{21}$ En el imperativo va antes de la palabra verbal y en el yusivo, en lugar del "positivo" ma.
a. [š-k-áhsi]
kleófas
IMPR-3 SG.O-agarrar
Cleofas
‘Agarra a Cleofas!' (XAL)
b. [máka š-k-áhsi] kleófas
NEG:INJ IMPR-3SG.O-agarrar Cleofas
‘No agarres a Cleofas!' (XAL)

21 Como ya se dijo, en Oapan el injuntivo negativo es [ma:] debido a la elisión de la [k] intervocálica. 
(87) a. [ma čičímeh micttoká-ka:n]

EXH perros te sigan-PL

'Que te sigan los perros.' (XAL)
b. [máka
čičímeh
miфtoká-ka:n]
NEG:INJ
perros
te sigan-PL
'Que no te sigan los perros.' (XAL)

(88) [má:ka sa: š-čí:wa] ruído [má:ka sa: ti- $\lambda$ áto:-s] NEG:INJ ya IMPR-hacer ruido NEG:INJ ya 2SG.SJ-hablar-POT 'Ya no hagas ruido. Ya no hables.' (ozo: Amith 2009: 170)

Obsérvese cómo en (88) se emplean los dos recursos injuntivos: el imperativo en la primera parte y el potencial, en la segunda.

Como es de esperarse, en las construcciones con oraciones subordinadas, cada una lleva la marca de negación que le corresponde: si el verbo va en yusivo, con el injuntivo negativo (89), si va en potencial, puede ser tanto con el injuntivo negativo como con el proclítico (90):

š=o-ki-na:wátih [má:ka ki-ma:íli:] í-kniw NEG-PF-3SG.O-pedir NEG:INJ 3SG.O-golpear 3SG.POS-hermano 'No le ordenó que no le pegara a su hermano.' (AHUE)

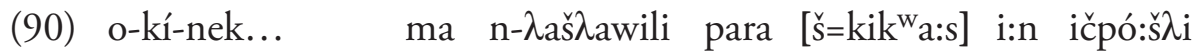
PF-3SG.O-DES:PF EXH 1sG.SJ-pagar para NEG=Coma DT muchacha 'Quiso... que yo le pagara para que no se comiera a la muchacha.'

(OAP: Amith 2009: 78) 


\section{El CONDiCional NEgativo ELÍPTico}

Tanto la prótasis como la apódosis de las construcciones condicionales puede ir negada empleando el proclítico de negación. La marca condicional $\lambda a$ : déke o déki antecede a la oración pero no forma parte de la palabra verbal compleja. Esto es, si la construcción va negada, el condicional no hospeda al proclítico.

(91) [déke ki-piá-s] [š=ák-a ipan ki-ta-s] CND 3SG.O-tener-POT NEG=alguien-INDF en 3SG.O-ver-POT 'Si lo tuviera, nadie lo vería.' (AmE: Amith 2009: 104)

(92) [déke š=ni-mis-či:wili:-skiá téki入] [téwa y-o-timih-ka] CND NEG=1sG.SJ-2sG.o-hacerle-CND trabajo tú ya-PF-morir-PPF 'Si yo no te hubiera hecho el trabajo, tú ya te hubieras muerto.'

(AME: Amith 2009: 134)

(93)
[á:man i:n kóyo: $\lambda$ né:č-kwa:-s] [ $\mathrm{\lambda a}$ : ahora DT coyote 1sG.O-comer-POT CND

$\check{s}=$ ni-k-maka-s]

NEG=1 SG.SJ-3 SG.O-dar-POT

'Ahora el coyote me va a comer... si no le diera (un pollo).'

(ozo: Amith 2009: 171)

En los casos en los que aparece negada la prótasis sin frase verbal ('si no...') se emplea el marcador negativo $\lambda a ́ b m o$ que, por sí mismo, es una 
oración (obsérvese cómo en 95 se usa tanto la forma náhuatl, como la española):

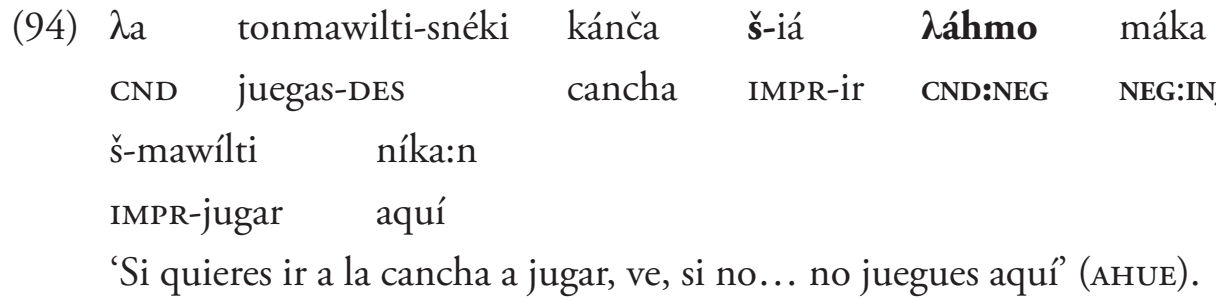

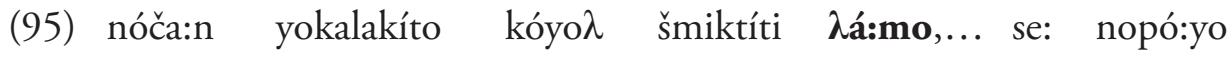
mi casa entró coyote mátalo CND:NEG un mi pollo

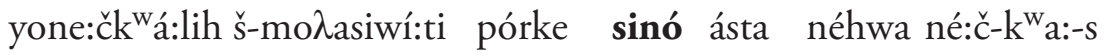
me lo coma IMPR-apurarse porque si no hasta yo 1so-comer-POT 'Un coyote se fue a meter a mi casa. Ve a matarlo. Si no, se comerá mis pollos. Apúrate, porque si no, hasta a mí me andará comiendo’ (ozo: Amith 2009: 171)

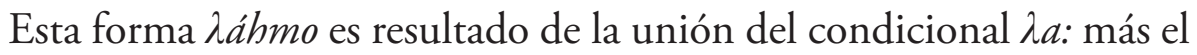
marcador negativo ábmo, propio de otras variantes nahuas.

\section{LA CONJUNCIÓN NEGATIVA Y EL CUANTIFICADOR NOMINAL NEGATIVO}

La conjunción negativa nin es un término de polaridad negativa, puesto que es necesaria la presencia del proclítico negativo en el verbo para que la oración sea aceptable. De hecho, tanto en los predicados verbales 
como en los no verbales, la presencia de dicha conjunción es optativa (y, de hecho, no es muy usada):

a. Sitlali $\check{s}=\lambda \operatorname{á}^{\mathrm{w}} \mathrm{a} \quad$ wan $\quad \check{s}=$ kóči

Citlali NEG=comer CNJ NEG=dormir

'Citlali ni come ni duerme.' (AHUE)

b. Sitlali nin $\quad \check{s}=\lambda a ́ k^{\mathrm{w}} \mathrm{a} \quad$ nin $\quad \check{s}=k_{\text {ḱčci }}$

Citlali CNJ:NEG NEG=comer CNJ:NEG NEG=dormir

'Citlali ni come ni duerme.' (AHUE)

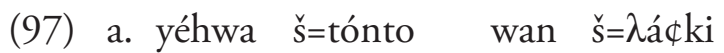

él NEG=tonto CNJ NEG=flojo

'Ella no es ni tonta ni floja.' (AHUE)

b. yéhwa š=tónto nin $\quad \check{s}=\lambda$ ácki

él NEG=tonto CNJ:NEG NEG=flojo

'Ella no es ni tonta ni floja.' (AHUE)

Sin embargo, tanto el nin como el niú:n (que pueden ir seguidos del numeral se 'uno', significando justamente 'ni uno', a pesar de que niú:n "ya lo significa") pueden formar parte de frases nominales, precediendo al sustantivo nuclear y funcionando en estos casos como cuantificadores nominales negativos (equivalentes a 'ninguno'). De todas maneras, en estos casos el verbo de las oraciones en las que aparecen estas frases nominales debe llevar su proclítico negativo. Esto es lo que me permite 
tratarlos en este mismo apartado a pesar de que cumplen funciones distintas.

En los ejemplos siguientes, las frases nominales que llevan el cuantificador nominal negativo juega distintas funciones sintácticas. En (98) y (99), ambas frases nominales preceden al verbo y son parte del sintagma sujeto (en la primera, el nin se aparece como un cuantificador; en la segunda, el nin como una conjunción). En (100), las frases nominales van después del verbo que, como ya se apuntó, va negado:

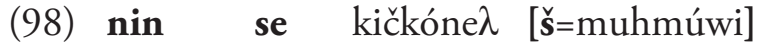

CNJ:NEG uno nińo NEG=temer

'Ningún niño tiene miedo.' (AHUE)

(99) nin múkniw [ř ${ }^{\mathrm{w}}=$ owáhlah] nóčan

CNJ:NEG tu hermano NEG=venir:PF mi casa

'Ni tu hermana vino a mi casa.' (AHUE)

(100) [šok o:kálak] u:n yó:lki, [šok o:kikwa:lí:to] u:n ší:lo:入 u:n ya no entró DT animal ya no comieron DT jilote DT kihlián kuwpiđómeh, niú:n kihlián tešó:meh, le dicen jabalíes CNJ:NEG le dicen tejones niú:n kihlián osto: \iđíinte. CNJ:NEG le dicen zorras

'Ya no entró ningún animal. Ya no se comieron sus jilotes ni los nombrados jabalíes ni los nombrados tejones ni los nombrados zorras.'

(AME: Amith 2009: 106) 
En las oraciones (101) y (102), las frases nominales son parte del sintagma objeto y en (103), como parte de una frase preposicional. En todos estos casos, el verbo va negado.

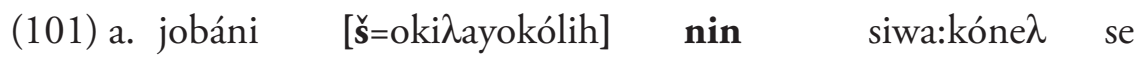
Jovanni NEG=regalar:PF CNJ:NEG niña un фopélik dulce 'Jovanni no le regaló ningún dulce a ninguna niña.' (AHUE)

b. [š=ni-kíta] $\quad$ nin $\quad$ se síwa: $\lambda$ čo:kátikah NEG=1 PL.SJ-3SG.O-ver CNJ:NEG uno mujer llora:PRG 'No veo a ninguna señora llorando.' (AHUE).

(102) a. t-ásis kánah niu:n tó:to: $\lambda \quad[\check{s}=\mathrm{ok}$ 2SG.SJ-llegar donde CNJ:NEG pájaro NEG=aún ti-k-ítas] 2SG.SJ-3SG.O-ver:POT 'Vas a llegar a donde ya no verás ni un pájaro.' (AME: Amith 2009: 127)

b. [šs=káman kipiá] $\lambda$ ayó:hli niú:n se: iburíto NEG=cuándo tiene maíz CNJ:NEG uno su burrito [šs=ki-piá] NEG=3SG.O-tener

'Nunca tiene maíz. Ni su burrito tiene.' (AME: Amith 2009: 105) 
(103)

[řs=o-ni-miф-íta-k] pan nin se siyéta
NEG=PF-1SG.SJ-2SG.O-ver-PF en CNJ:NEG uno silla

'No te vi en ninguna silla.' (AHUE)

Estos nin o niun no forman parte de la palabra verbal compleja, por ello no llevan el proclítico negativo aunque aparezcan antecediendo al verbo.

(104) kihliá, “niú:n se: [řs=k-ona:náskeh!]”

le dice CNJ:NEG uno NEG=3.OBJ-agarrar:POT:PL

'Le dice: "No agarrarán ni una sola."' (AME: Amith 2009: 142)

(105) yá:ya ína:k doktór, péřo niú:n a:čícii:n [š=ki-či:wiá:ya] iba con doctor pero CNJ:NEG poquito NEG=3.OBJ-hacer přobečo. provecho

'Iba a ver al doctor pero no le hacía ni un poquito de provecho.'

(AME: Amith 2009: 110)

Todo parece indicar que este niú:n le añade un énfasis de negación a la construcción, es por esto que tanto en (106) como en (107) he traducido la construcción negativa como 'para nada' o 'ni siquiera'. 
(106) ¡yo:wéka:w timonono:stókeh! péřo niú:n šnimistlato:ltiá ké:no:n motó:ka:.

'Ya hemos estado platicando por un rato pero para nada te he preguntado tu nombre.' (Lit. '... pero no te pregunto ni cómo es tu nombre'.)

(AME: Amith 2009: 108)

(107) Péřo Pédro niú:n škimáti déke ipá:mpa yo:tlató:lo:k. šnomaka ké:ntah. 'Pero Pedro para nada sabe si se habló por él. No se da cuenta.'

(AME: Amith 2009: 106)

Si la oración en la que aparece el niú:n lleva algún negativo absoluto (véase $\$ 2.5$ ), este último precede al niú:n, a pesar de cumplir con la función de cuantificador nominal negativo.

(108) pára se: $\lambda$ áçki [š̀ah] niú:n se: $\lambda$ aškáhli wa:n para uno flojo nada CNJ:NEG uno tortilla CNJ

[š̀ah] niú:n se: sentábo

nada CNJ:NEG uno centavo

'Para un flojo, nada, ni una sola tortilla y ni un solo centavo.'

(AME: Amith 2009: 109) 


\section{Comentarios Finales}

En este texto se describen los cinco exponentes que tiene el marcador negativo en el náhuatl del centro de Guerrero o Alto Balsas. La atención principal se ha centrado en la negación estándar, en varias de sus formas, y se han descrito muy someramente los recursos morfosintácticos para negar. Queda pendiente profundizar sobre otros temas relacionados con el fenómeno de la negación.

Tres cosas vale la pena señalar: la primera, que morfológicamente la negación estándar se marca con un proclítico $\{\check{s}=\}$, la segunda, que este proclítico ocupa la primera posición en la palabra verbal compleja y, la tercera, que las formas empleadas para negar las construcciones predicativas locativas o existenciales cuando el sujeto es humano o humanizado, son $a k-a: k$. 


\section{Abreviaturas}

\begin{tabular}{|c|c|c|c|c|c|}
\hline AHUE & Ahuelicán & IMPS & 'Impersonal' & PT & 'Pasado' \\
\hline AME & Ameyaltepec & INDF & 'Indefinido' & RFX & 'Reflexivo' \\
\hline ASP & 'Aspecto' & INJ & 'Injuntivo' & XAL & Xalitla \\
\hline CND & 'Condicional' & INST & 'Instrumental' & 1PL.POS & '1 a plural posesivo' \\
\hline $\mathrm{CNJ}$ & ‘Conjunción’ & INT & 'Interrogativo' & 1PL.SJ & '1 $1^{a}$ plural sujeto' \\
\hline CUOT & 'Cuotativo' & INTJ & 'Interjección' & 1sG.O & '1a singular objeto' \\
\hline DEM & 'Demostrativo' & NEG & 'Marcador negativo' & 1sG.POS & ' 1 a singular posesivo' \\
\hline DES & 'Desiderativo' & OAP & Oapan & 1sG.SJ & '1 a singular sujeto' \\
\hline DIM & 'Diminutivo' & OzO & Ozomatlán & 2SG.O & '2a singular objeto' \\
\hline $\mathrm{DR}$ & 'Direccional' & $\mathrm{PF}$ & 'Perfecto' & 2SG.POS & ' $2^{\mathrm{a}}$ singular posesivo' \\
\hline DT & 'Determinante' & PL & 'Plural' & 2SG.SJ & '2a singular sujeto' \\
\hline EXH & 'Exhortativo' & PROG & 'Progresivo' & 3 PL.O & '3a plural objeto' \\
\hline IMPF & 'Imperfecto' & РОт & 'Potencial & 3SG.O & ' $33^{a}$ singular objeto' \\
\hline IMPR & 'Imperativo' & PPF & 'Plusperfecto' & 3SG.POS & ' 3 a singular posesivo' \\
\hline
\end{tabular}

\section{REFERENCIAS}

Amith, Jonathan D. (ed). 2009. Ok nemi totlahtol. Volumen 1. Estado de Guerrero. México: Instituto Nacional de Lenguas Indígenas. Bond, Oliver. 2007. Towards a canon for negation. En Austin, Peter K. \& Bond, Oliver \& Nathan, David (eds.), Proceedings of Conference on Language Documentation and Linguistic Theory, 39-49. London: School of Oriental and African Studies. 
Brockway, Earl \& de Brockway, Trudy Hershey \& Santos, Leodegario. 2000. Diccionario náhuatl del norte del estado de Puebla. México: Instituto Lingüístico de Verano, A.C./Universidad Madero.

Buenrostro, Cristina (ed.). 2010. Presentación. Lingüistica Mexicana 2. 189-191.

Dahl, Östen. 1979. Typology of sentence negation. Journal of Linguistics 17. 79-106.

Hengeveld, Kees. 1992. Non-verbal predication. Theory, typology, diachrony. Berlín: Mouton de Gruyter.

Herrera, Carmen \& Ramírez, Alfredo \& Alvarado, Maribel. 2012. Un panorama de la negación del alto río Balsas. (Ponencia presentada en el $V$ Coloquio Leonardo Manrique.)

Hill, Jane. 2005. A grammar of Cupeño (University of California Publications in Linguistics 136). Berkeley: University of California Press.

Jakobson, Roman. 1985 [1974]. Ensayos de lingüistica general. México: Origen/Planeta.

Lastra, Yolanda. 1980. El náhuatl de Tetzcoco en la actualidad. México: Instituto de Investigaciones Antropológicas/Universidad Nacional Autónoma de México.

Lastra, Yolanda. 1986. Las áreas dialectales del náhuatl moderno. México: Instituto de Investigaciones Antropológicas/Universidad Nacional Autónoma de México.

Launey, Michel. 1992 [1979]. Introducción a la lengua y la literatura nábuatl. México: Instituto de Investigaciones Antropológicas/Universidad Nacional Autónoma de México. 
Miestamo, Matti. 2000. Towards a typology of standard negation. Nordic Journal of Linguistics 23. 65-88.

Miestamo, Matti. 2007. Negation. An overview of typological research. Language and Linguistics Compass 1(5). 552-570.

Miestamo, Matti. 2013. Symmetric and Asymmetric Standard Negation. En Dryer, Matthew S. \& Haspelmath, Martin (eds.), The World Atlas of Language Structures Online. Leipzig: Max Planck Institute for Evolutionary Anthropology. http://wals.info/chapter/113 (Consultado el 06-04-2016.)

Payne, John. R. 1985. Negation. En Shopen, Timothy (ed.), Language typology and syntactic description. Vol. I, Clause structure, 197-242. Cambridge: Cambridge University Press.

Wolgemuth, Carl. 2007. Nahuatl grammar of the townships of Mecayapan and Tatahuicapan de Juárez, Veracruz. 2nd edn. https://sites.ualberta.ca/ - csmackay/Mecayapan.pdf. (Consultado el 11-07-2016.) (Traducción de Christopher S. Mackay.) 